\title{
Optimization of electrospinning process of poly(vinyl alcohol) via response surface methodology (RSM) based on the central composite design
}

\author{
Mina Yazdanpanah ${ }^{\mathrm{a}^{*}}$, MohammadReza Khanmohammadi ${ }^{\mathrm{a}}$, Ruhollah Mehdinavaz Aghdam ${ }^{\mathrm{b}}$, Keyvan \\ Shabani ${ }^{\mathbf{b}}$ and Masoud Rajabi ${ }^{\mathrm{a}}$
}

${ }^{a}$ Chemistry Department, Imam Khomeini International University, Qazvin, Iran ${ }^{b}$ Department of Nanotechnology, Engineering Research Institute, Tehran, Iran CHRONICLE ABSTRACT

Article history:

Received January 22, 2014

Received in revised form

February 02, 2014

Accepted 3 May 2014

Available online

3 May 2014

Keywords:

Electrospinning

Fiber

Variables

Optimization

\begin{abstract}
Evaluating the capability of electrospinning method as an efficient versatile approach for fabrication of fibers, a central composite design (CCD) model was used to design an experimental program for investigation of effective in production of poly (vinyl alcohol) (PVA) fibers fabricated from aqueous solutions of PVA. The studied variables were polymer solution concentration, applied voltage, distance between nozzle and collector plate and flow rate of solution injection. The influence of these parameters on diameter and morphology of obtained PVA fibers was studied by SEM analysis. Among all factors, concentration would strongly affect the fiber diameter.
\end{abstract}

\section{Introduction}

Electrospinning is known as the most common and economical technique for producing polymer fibers with diameters ranging from $2 \mathrm{~nm}$ to several micrometers ${ }^{1-3}$. The fabricated polymer nanofibers offer several advantages such as, extremely high surface-to-volume ratio, superior mechanical properties etc. Considering these advantages, nanofibers can find wide applications in various areas such as filtration, optical and chemical sensors, electrode materials, biological and engineering scaffolds, catalyst supports and drug delivery systems ${ }^{4-8}$. Polyvinyl alcohol (PVA) is a water-soluble polymer used in fabrication of polymeric fibers due to its excellent chemical and physical properties, non-toxicity, process ability, good chemical resistance, complete biodegradability, etc ${ }^{9}$. Main parameters which are known to affect the electrospinning process are specific solution properties such as the type of polymer, polymer solution concentration, viscosity, surface tension, electrical conductivity, electrical field strength, fluid flow rate and environmental humidity ${ }^{10-12}$. Therefore, it is

\footnotetext{
* Corresponding author. Fax: +982166479110

E-mail address: m.yzdpanah@yahoo.com (M. Yazdanpanah)
} 
important to systematically investigate the effect of parameters on experimental output. Design of experiment (DOE) has been recognized as a suitable tool for investigating and optimizing the effect of parameters on PVA fiber diameter and it can be favored to decrease the number of experiments. Among different approaches, central composite design (CCD) is an appropriate experimental design method which provides high quality predictions in studying linear, quadratic and interaction effects of parameters that influence a system ${ }^{13-14}$. Furthermore, one of the efficient techniques for obtaining the optimum conditions in a multivariable system is response surface methodology (RSM) ${ }^{15-16}$. Recently, this technique has been successfully used for different processes to achieve the optimized condition using RSM e.g. "fiber spinning processes including dry-jet-wet spinning of polyurethane elastomeric fibers, electrospinning of silk fibers fabrication of poly (lactide) fibers and poly (acrylonitrile) fibers 17,. Recently RSM has been also applied for predicting the nanofiber diameter of electrospun titanium dioxide (TiO2) nanofibers.

\section{Material and methods}

\subsection{Materials, apparatus and softwares}

PVA (high molecular weight; hydrolysis 98\%-99\%) was purchased from Alfa Aesar (USA). Double distilled water was used as a solvent in fabrication procedure. The morphology and diameter of electrospun fibers was analyzed by scanning electron microscope (SEM, Philips, XL, Germany) after gold coating. The statistical software package Design expert version 7, USA was used for regression analysis of experimental data.

\subsection{Experimental design}

There are three main steps for experimental design as follows; conducting the statistically designed experiments, estimating the coefficients in a mathematical model for predicting the responses and checking the applicability of the model ${ }^{18}$. In this study, CCD and RSM were used to explore the optimum conditions in preparation of PVA fibers with the least diameter and the best morphology. The studied factors were PVA solution concentration $\left(\mathrm{X}_{1}\right)$, applied voltage $\left(\mathrm{X}_{2}\right)$, collector distance from nozzle $\left(\mathrm{X}_{3}\right)$, and flow rate $\left(\mathrm{X}_{4}\right)$ where the studied parameters which their levels are given in Table 1.

Table 1. The variables and their levels for the central composite experimental design

\begin{tabular}{ccccc}
\hline Factor & Name & Units & $\min$ & Max \\
\hline $\mathrm{X}_{1}$ & Concentration & $\% \mathrm{wt}$ & 6.00 & 10.00 \\
$\mathrm{X}_{2}$ & Voltage & $\mathrm{kV}$ & 18 & 24.00 \\
$\mathrm{X}_{3}$ & Distance & $\mathrm{Cm}$ & 9.50 & 12.50 \\
$\mathrm{X}_{4}$ & Flow rate & $\mu \mathrm{lit} / \mathrm{min}$ & 6.00 & 12.00 \\
\hline
\end{tabular}

The designed experimental model included 30 experimental trials which have six trials as replication of the central points. A standard Analysis of variance (ANOVA) was then carried out to analyze the response surface models. All experiments were performed in a random order.

\subsection{Preparation of PVA solutions and electrospinning of PVA}

In the first step, distilled water was added to PVA and the mixture was stirred in a capped vessel for $24 \mathrm{~h}$ at $50^{\circ} \mathrm{C}$. Based on experimental design, certain solution concentration was loaded into a syringe equipped with a stainless steel needle and fibers were prepared. Electrospinning setup consisted of a syringe and needle, a grounded electrode (aluminum foil), and a high voltage supply. The distance between syringe needle and collecting plate was adjustable. The programmable pump could control the flow rate of polymer solutions by pushing the syringe. In this work, the syringe 
needle was connected to high voltage power supply. In the electrospinning process, a high electric potential at the range of 15-24 kV was applied to a droplet of PVA precursor solution at the tip of a syringe needle with $0.4 \mathrm{~mm}$ inner diameter. The electrospun fibers were collected on a target plate (aluminum foil), which was placed at $8-14 \mathrm{~cm}$ from the syringe tip. A syringe pump was used to provide a constant flow of PVA precursor solution at the tip. The output of the injection pump was between 3 and $12 \mu \mathrm{l} / \mathrm{min}$. A charged jet was formed and ejected towards the applied field. As the PVA precursor solution jet travels in the air, most of the solvent evaporates and the fiber was collected on the grounded target as fine fibers .All electrospinning progress were carried out at room temperature.

\subsection{Characterization of prepared PVA fiber samples}

SEM with accelerating voltages from $20-25 \mathrm{kV}$ was used for microscopic imaging and analysis. For observation of fibers with SEM the fibers were coated with gold using a sputtering technique. The average fiber diameter of fibers was determined by analyzing SEM images with microstructure measurement software.

\section{Results and Discussion}

\subsection{Determination of fiber diameter by SEM}

As mentioned before, all the samples were studied by SEM to determine their fiber diameter. In order to obtain more reliable data, by microstructure measurement software, 60 points of each sample were analyzed and the fiber diameter range was also reported. It was clearly observed that the fiber diameter of final product depends on designed parameters during the synthesis procedure. The smallest average fiber diameter was $211 \mathrm{~nm}$ while the largest one was $645 \mathrm{~nm}$. SEM images from these samples are shown in Fig. 1.

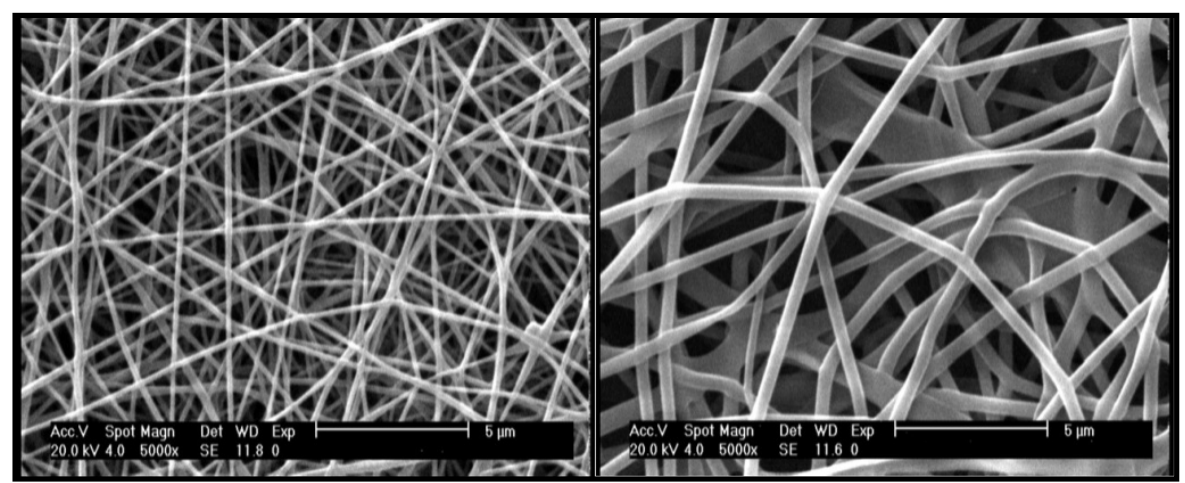

Fig. 1. SEM images of samples with a) smallest fiber diameter and b) largest fiber diameter.

\subsection{Diameter optimization by CCD}

\subsubsection{Estimation of coefficients in a mathematical polynomial function}

After performing a set of experiments to obtain outputs according to the experimental designs, the next step was to consider the vectors of variables (X) and corresponding respond (Y) developing an appropriate model. For a quadratic model, experiments must be conducted at least at three levels for each factor. Polynomial is a most common mathematical function in RSM. A typical response surface function for four input variables is in the form of following equation: 
$\mathrm{y}=\mathrm{b}_{0}+\mathrm{b}_{1} \mathrm{x}_{1}+\mathrm{b}_{2} \mathrm{x}_{2}+\mathrm{b}_{3} \mathrm{x}_{3}+\mathrm{b}_{4} \mathrm{x}_{4}+\mathrm{b}_{12} \mathrm{x}_{1} \mathrm{x}_{2}+\mathrm{b}_{13} \mathrm{x}_{1} \mathrm{x}_{3}+\mathrm{b}_{14} \mathrm{x}_{1} \mathrm{x}_{4}+\mathrm{b}_{23} \mathrm{x}_{2} \mathrm{x}_{3}+\mathrm{b}_{24} \mathrm{x}_{2} \mathrm{x}_{4}+\mathrm{b}_{34} \mathrm{x}_{3} \mathrm{x}_{4}+$

$\mathrm{b}_{11} \mathrm{x}_{1}^{2}+\mathrm{b}_{22} \mathrm{x}_{2}^{2}+\mathrm{b}_{33} \mathrm{x}_{3}^{2}+\mathrm{b}_{44} \mathrm{x}_{4}^{2}$

The results of the response surface model fitting in the form of ANOVA are given in Table 2.

Table 2. Analysis of variance of the model

\begin{tabular}{lllll}
\hline & Sum of squares & Mean squares & F Value & Prob(p) $>$ F \\
\hline Model & 63507.59 & 14873.53 & 17.58 & $<0.0001$ \\
Residual error & 12693.77 & 846.25 & & \\
Lack of fit & 9870.84 & 987.08 & 1.75 & 0.2793 \\
Pure error & 2846.81 & 569.36 & & \\
\hline
\end{tabular}

The Fisher F-test with a very low probability value $(\mathrm{p}>\mathrm{F}=0.0001)$ demonstrates a high significance for the regression model. The efficiency of correlated model was checked by the correlation coefficient $\left(\mathrm{R}^{2}\right)$. In the obtained model, $\left(\mathrm{R}^{2}=0.94\right)$ indicates that only $6 \%$ of the total variations are not explained by the model. The value of the adjusted $\mathrm{R}^{2}=0.88$ is also high to advocate a high significance of the model. Table 2 shows the results of analysis of variance of this model. The importance of each coefficient was determined by the p-values so; smaller p-values corresponded to the more important coefficients. The application of response surface methodology yielded the Eq. (2) which is final Equation in terms of coded factors:

$$
\begin{aligned}
& Y=+296.1+75.59 X_{1}-9.45 X_{2}-3.99 X_{3}+6.31 X_{4}-1.91 X_{1} X_{2}-7.64 X_{1} X_{3}+8.98 X_{1} \\
& X_{4}-1.66 X_{2} X_{3}-9.38 X_{2} X_{4}+3.84 X_{3} X_{4}+41.04 X_{1}^{2}-10.18 X_{2}^{2}-3.91 X_{3}^{2}-14.19 X_{4}^{2}
\end{aligned}
$$

where $Y$ is the response (the fiber diameter) and $X_{1}, X_{2}, X_{3}$ and $X_{4}$ are the values of the test variables shown in Table 2. This equation suggests a direct relationship between PVA concentrations with fiber diameter. These observation indicate the concentration of PVA is the most significant (scaled estimate $=+75.59$ ) parameter in electrospinning of PVA fiber. Except for the linear term X1 (PVA concentration), quadratic terms $\mathrm{X}_{1}^{2}$ (PVA content) and $\mathrm{X}_{4}^{2}$ (flow rate) $(\mathrm{p}<0.05)$, none of the other linear, quadratic and interaction terms were statistically significant. Thus the summarized equation according to critical parameters would be:

$\mathrm{Y}=+296.23+75.59 \mathrm{X}_{1}+41.04 \mathrm{X}_{1}^{2}-14.19 \mathrm{X}_{4}^{2}$

predicted fiber diameter versus actual fiber diameter diagram is shown in Fig. 2.

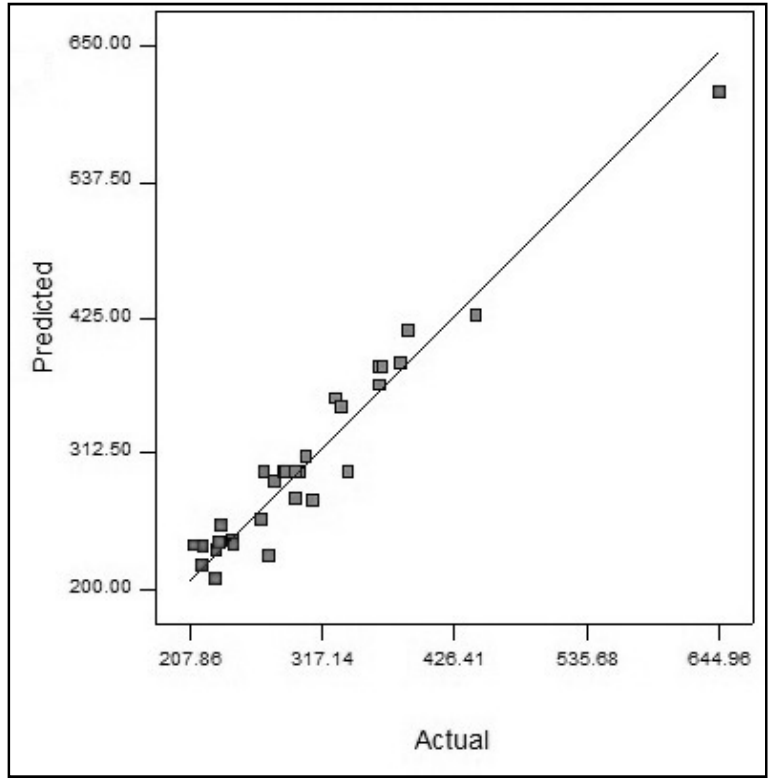

Fig. 2. predicted fiber diameter versus actual fiber diameter diagram 
The theoretical diameter of fibers obtained from optimum conditions were $296.1 \mathrm{~nm}$. SEM image of fibers fabricated at optimized conditions is shown in Fig. 3 which was determined to be $300 \pm 15$.

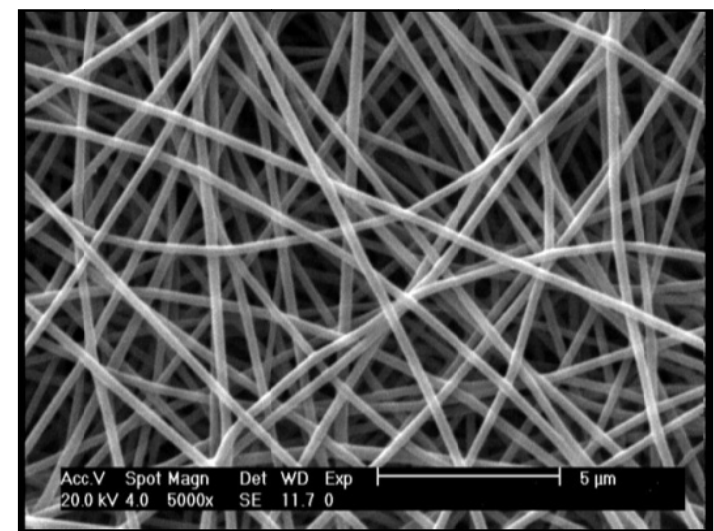

Fig. 3. SEM image of PVA fiber with optimum diameter.

\subsubsection{Evaluation of the theoretical optimum point: response surface and contour plots}

The predicted values of $\mathrm{Y}$ (fiber diameters) based on the range of variables in RSM were estimated as response surface plot which is a theoretical three-dimensional scheme to explain the relationship between the response and independent variables visually (Fig. 4); and contour plot which is the two-dimensional display of the surface plot is called contour plot and constant response's lines are drawn in the independent variables' plane. These 2-D plots are helpful in visualization of response surface shape(Fig. 5).

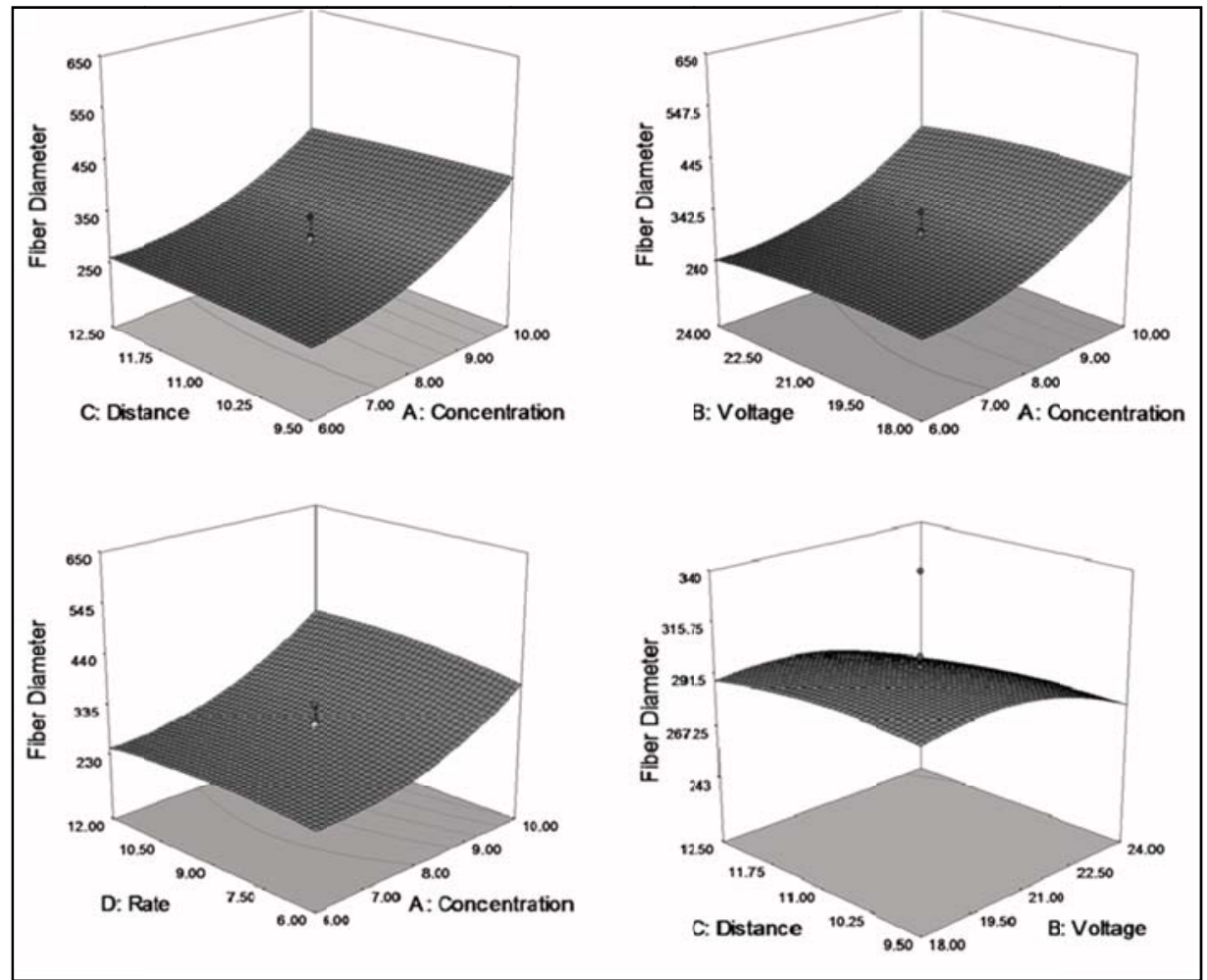

Fig. 4. Response surface plots on fiber diameter: effect of (a) PVA concentration and distance, (b) voltage and PVA concentration, (c) flow rate and PVA concentration and (d) distance and voltage and their interaction on the fiber diameters 


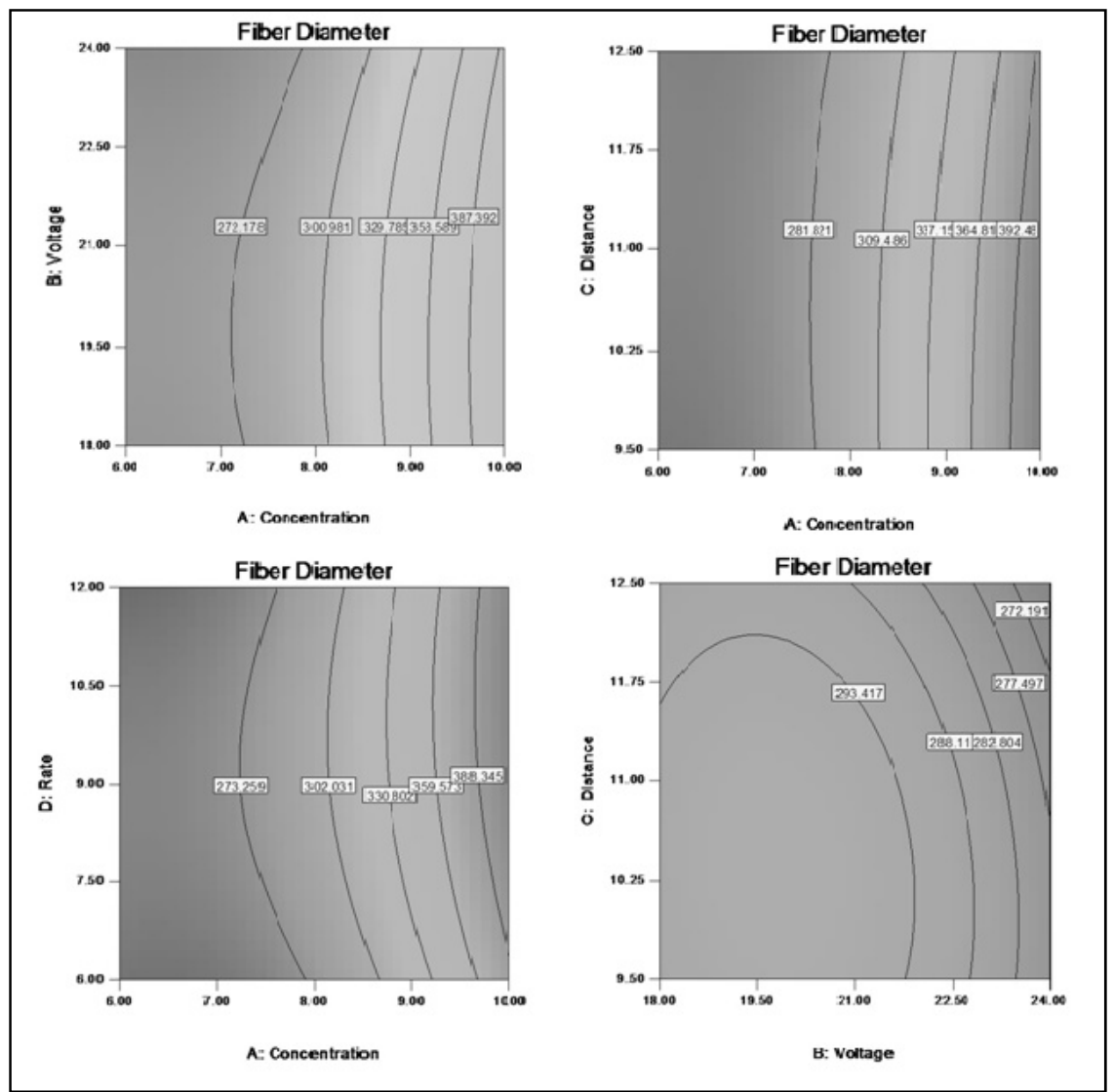

Fig. 5. Contour plots of the fibers diameter (nm): the effect of PVA concentration, voltage, distance, flow rate and their mutual interaction on diameter of produced fibers

Maximum or minimum response is achieved on the system center if the contour plot displays ellipses or circles. It is mentionable that hyperbolic or parabolic contours may sometimes occur. If quadratic term is effective on the response plot, it would become curvature and in this situation the stationary point is called a saddle point (neither a maximum nor a minimum point). While the model fitting capabilities is well provided by useful information of these plots, the true behavior of the system is not presented. One must not forget the contours (or surfaces) represent contours of estimated response and the general nature of the system arises as a result of a fitted model, not the true structure ${ }^{19}$.

Each response surface presents the effect of any two factors on the fiber diameter while other factor is held at constant level. From the response surface plot in Figure 2(a), it is understood that fiber diameter decreases as PVA concentration decreases $\left(\mathrm{X}_{1}\right)$. Increasing distance $\left(\mathrm{X}_{3}\right)$ in combination with decreasing concentration causes the fiber diameter to behave non-linearly. Similarly, it is also observed in Figure $2 \mathrm{~b}$ and $2 \mathrm{c}$ that there are some interactions between the concentration $\left(\mathrm{X}_{1}\right)$ and voltage $\left(\mathrm{X}_{3}\right)$ and between concentration $\left(\mathrm{X}_{1}\right)$ and flow rate $\mathrm{X} 4$. Similarly, it is also observed in Figure $2 \mathrm{~d}$ that there is a strong interaction between the concentration $\left(\mathrm{X}_{1}\right)$ and applied voltage $\left(\mathrm{X}_{2}\right)$. Figure 2(a) shows the linear effect of PVA concentration on fiber diameter. It can be concluded that as increasing the viscosity of polymer solution by concentrating, a larger volume of drop is formed on the tip head and the appropriate strain for formation of a narrow fiber is not provided, thus in higher viscosities obtained via increasing the concentration the fiber diameter would be larger. On the other hand by higher output currency on the tip head, the jet diameter is reduced due to the less staying time for the drop and faster spinning. Increasing the voltage would improve the electrical field and by this higher strain force, the fibers become smaller in diameter. 


\section{Conclusions}

The application of response surface methodology (RSM) in conjunction with central composite design (CCD) for optimizing of fiber diameter was discussed. The effect of various parameters on diameter of PVA fibers studied via SEM analysis. . Based on Response surface plots optimum conditions for fabricating PVA fibers with minimum diameter around $296 \mathrm{~nm}$ was attained. These conditions are as follow; concentration: $8 \% \mathrm{wt}$, distance: $11 \mathrm{~cm}$, voltage: $21 \mathrm{kV}$, flow rate: $9 \mu \mathrm{lit} / \mathrm{min}$. Predicted values from the model equations were found to be in good agreement with observed values $\left(\mathrm{R}^{2}=0.94\right)$.

\section{References}

1. Mu, X., Liu, Y., Fang, D., Wang, Z., Nie, J., and Ma, G. (2012) Electric field induced phase separation on electrospinning polyelectrolyte based core-shell nanofibers, Carbohyd. Polym., 90, 1582-6.

2. Barakat, N. A. M., Kanjwal, M. A., Sheikh, F. A., and Kim, H. Y. (2009) Spider-net within the N6, PVA and PU electrospun nanofiber mats using salt addition: Novel strategy in the electrospinning process, Polymer, 50, 4389-4396.

3. Singh, S., Singh, V., Vijayakumar, M., and Bhanu Prasad, V. V. (2012) ZrO2 fibers obtained from the halide free synthesis of non-beaded PVA/Zr n-propoxide electrospun fibrous composites, Ceram. Int., 39, 1153-1161.

4. Chronakis, I. S. (2005) Novel nanocomposites and nanoceramics based on polymer nanofibers using electrospinning process-A review, J. Mater. Process. Technol., 167, 283-293.

5. Bhardwaj, N., and Kundu, S. C. (2010) Electrospinning: A fascinating fiber fabrication technique, Biotechnol. Adv., 28, 325-347.

6. Liu, Y., Ma, G., Fang, D., Xu, J., Zhang, H., and Nie, J. (2011) Effects of solution properties and electric field on the electrospinning of hyaluronic acid, Carbohyd. Polym., 83, 1011-1015.

7. Tiwari, S. K., and Venkatraman, S. S. (2012) Importance of viscosity parameters in electrospinning: of monolithic and core-shell fibers, Mater. Sci. Eng., C., 32, 1037-1042.

8. Chae, H. H., Kim, B., Yang, K. S., and Rhee, J. I. (2011) Synthesis and antibacterial performance of size-tunable silver nanoparticles with electrospun nanofiber composites, Synth. Met., 161, 2124- 2128.

9. Uslu, I., Daştan, H., Altaş, A., Yayli, A., Atakol, O., and Aksu, M. L. (2013) Preparation and Characterization of PVA/Boron Polymer Produced by an Electrospinning Technique, e-Polymer 7 1568-1573.

10. Su, P., Wang, C., Yang, X., Chen, X., Gao, C., Feng, X., Chen, J., Ye, J., and Gou, Z. (2011) Electrospinning of chitosan nanofibers: The favorable effect of metal ions, Carbohyd. Polym., 84, 239-246.

11. Thompson, C. J., Chase, G. G., Yarin, A. L., and Reneker, D.H. (2007) Effects of parameters on nanofiber diameter determined from electrospinning model, Polymer, 48, 486913-6922.

12. He, J., Wu, Y., And Zuo, W. (2005) Critical length of straight jet in electrospinning, Polymer, 46, 12637-12640.

13. Pongstabodee, S., Monyanon, S., and Luengnaruemitchai, A., (2012) Applying a face-centered central composite design to optimize the preferential $\mathrm{CO}$ oxidation over a $\mathrm{PtAu} / \mathrm{CeO}_{2}-\mathrm{ZnO}$ catalyst, Int. J. Hydrogen Energy., 37, 4749 -4761.

14. Diler, E. A., and Ipek, R. (2012) An experimental and statistical study of interaction effects of matrix particle size, reinforcement particle size and volume fraction on the flexural strength of AlSiCp composites by P/M using central composite design, Mater. Sci. Eng., A., 548, 43- 55.

15. Aslan, N. (2008) Application of response surface methodology and central composite rotatable design for modeling and optimization of a multi-gravity separator for chromite concentration, Powder Technol., 185, 80-86. 
16. Cho, I., and Zoh, K. (2007) Photocatalytic degradation of azo dye (Reactive Red 120) in TiO2/UV system: Optimization and modeling using a response surface methodology (RSM) based on the central composite design, Dyes. Pigm., 75, 533-543.

17. Kong, L., and Ziegler, G. R. (2013) Quantitative relationship between electrospinning parameters and starch fiber diameter, Carbohyd. Polym., 92, 1416-22.

18. Sarlak, N., Farahmandnejad, M. A., Shakhesi, S., and Shabani, K. ,(2012) Effects of electrospinning parameters on titanium dioxide nanofibers diameter and morphology: An investigation by Box-Wilson central composite design (CCD), Chem. Eng. J., 210, 410-416.

19. Myer, R. H., Montgomery, D. C., \& Cook, C. M. A. (2002) Response Surface Methodology: Process and Product Optimization Using Designed Experiments. NJ, USA: 2st ed., John Wiley and Sons Inc,. 